\title{
The 'Exposed' Population, Violent Crime in Public Space and the Night-time Economy in Manchester, UK
}

\author{
Muhammad Salman Haleem ${ }^{1}$ (D) $\cdot$ Won Do Lee ${ }^{1,2}$ (D) $\cdot$ Mark Ellison $^{1} \cdot$ Jon Bannister ${ }^{1}$
}

Published online: 20 June 2020

(C) The Author(s) 2020

\begin{abstract}
The daily rhythms of the city, the ebb and flow of people undertaking routines activities, inform the spatial and temporal patterning of crime. Being able to capture citizen mobility and delineate a crime-specific population denominator is a vital prerequisite of the endeavour to both explain and address crime. This paper introduces the concept of an exposed population-at-risk, defined as the mix of residents and non-residents who may play an active role as an offender, victim or guardian in a specific crime type, present in a spatial unit at a given time. This definition is deployed to determine the exposed population-at-risk for violent crime, associated with the night-time economy, in public spaces. Through integrating census data with mobile phone data and utilising fine-grained temporal and spatial violent crime data, the paper demonstrates the value of deploying an exposed (over an ambient) population-at-risk denominator to determine violent crime in public space hotspots on Saturday nights in Greater Manchester (UK). In doing so, the paper illuminates that as violent crime in public space rises, over the course of a Saturday evening, the exposed population-at-risk falls, implying a shifting propensity of the exposed population-at-risk to perform active roles as offenders, victims and/or guardians. The paper concludes with a discussion of the theoretical and policy relevance of these findings.
\end{abstract}

Keywords Exposed population-at-risk $\cdot$ Mobile phone data $\cdot$ Violent crime $\cdot$ Public space $\cdot$ Nighttime economy $\cdot$ Routine activity theory

Muhammad Salman Haleem

m.haleem@mmu.ac.uk

Won Do Lee

wondo.lee@ouce.ox.ac.uk

1 Crime and Well-being Big Data Centre, Manchester Metropolitan University, 4 Rosamond Street West, Manchester M15 6LL, UK

2 Transport Studies Unit, School of Geography and the Environment, University of Oxford, South Parks Road, Oxford OX1 3QY, UK 


\section{Introduction}

Crime rate denominators require being calculated with reference to specific crime types (Boggs 1965) and with sensitivity to the temporal and spatial patterning of crime arising from the daily rhythms of city, the ebb and flow of people undertaking routine activities. Failure to meet these requirements may inflate or deflate the crime rate (Song et al. 2018), masking the true nature of the crime problem and impeding its effective address. In advance of previous studies, and informed by routine activities theory (Cohen and Felson 1979), this paper introduces the concept of an exposed population-at-risk, defined as the mix of residents and non-residents who may play an active role as an offender, victim or guardian in a specific crime type, present in a spatial unit at a given time. Examining violent crime, associated with the night-time economy (NTE), in public space and on Saturday evenings in Greater Manchester (UK), we evaluate the value of employing an exposed population-at-risk measure in contrast to an ambient population-at-risk measure (Andresen 2011) in identifying crime hotspots. This exercise is underpinned through the utilisation and integration of both novel and fine-grained mobile phone and crime data sets. Having established a theoretically informed definition of the exposed population-at-risk of violent crime in public space, of the (potential) temporally shifting propensities of this population to perform an active role as an offender, victim or guardian, the research progresses to address the following questions:

- RQ1: What is the spatial and temporal patterning of violent crime in public space?

- RQ2: Does the exposed or ambient population-at-risk hold a greater correlation with the spatial and temporal patterning of violent crime in public space?

- RQ3: What is the distinction between the violent crime in public space hotspots generated by exposed and ambient population-at-risk measures?

- RQ4: Is late-evening violent crime in public space associated with a declining exposed population-at-risk?

\section{Background}

Crime holds an uneven spatial and temporal distribution, concentrating in particular urban areas (Sherman et al. 1989; Weisburd et al. 2012) and at specific times of the week or day (Brunsdon et al. 2007; Newton 2015; Townsley 2008). Crime hotspots occur where and when crime counts are significantly higher compared to other spatial units and time periods (Chainey and Ratcliffe 2005). Crime hotspots are, at least in part, a function of the size of the population present in a spatial unit at a given time; it has long been held that there is a general positive cross-sectional relationship between population size and crime (Braithwaite 1989; Siegel and Williams 2003). In other words, as population size increases we can typically expect crime to increase also, though we should be cautious in assuming a direct causal effect of population size on crime (Rotolo and Tittle 2006).

The population present in a spatial unit at a given time is the product of the daily rhythms of the city, the ebb and flow of people undertaking routine activities, providing a pool of motivated offenders, targets (victims) and guardians (Boivin 2018; Cohen and Felson 1979). Crime hotspots, therefore, at least for certain types of crime, are a 'manifestation of the flows of population more generally' (Malleson and Andresen 2016, p. 53). Being able to measure population flows, their influence upon the population size of a spatial unit at a given time is 
thus a vital component of any investigation of the cause of crime. The capture of an accurate population denominator enables the calculation of crime rates. Comparing crime rates across multiple spatial and temporal units facilitates the identification of disproportionate associations between population size and crime, places and moments in which the qualities of the people present and/or of the setting itself hold influence on a particular crime problem. This opens prospect of usefully supporting the design, implementation and evaluation of crime prevention and management strategies.

Static population measures, such as the residential and workplace population counts derived from the census, fail to capture the ebb and flow of urban populations, tending to overestimate or underestimate the population present in a spatial unit at a given time. Recognising this, Andresen (2011) proposed an ambient population count, based on the mix of residents and non-residents (or transient population) present in a spatial unit at a given time, as a more suitable population denominator. In response, multiple approaches for calculating an ambient population count have been advanced, including the integration of census (workplace and residential) data (Mburu and Helbich 2016; Stults and Hasbrouck 2015), the interpretation of satellite data (Andresen 2011), the utilisation of large travel surveys (Boivin and Felson 2018; Felson and Boivin 2015), the use of CCTV to estimate footfalls (Marselle et al. 2012), the assessment of mobile telephone activity (Bogomolov et al. 2014; Hanaoka 2018; Malleson and Andresen 2016; Song et al. 2018) and the evaluation of spatio-temporal twitter tags (Hipp et al. 2018; Malleson and Andresen 2015). Each of these approaches, based on the unique qualities of the data deployed (as recognised by the authors), hold limitations centred on the lack of comprehensive capture of the ambient population, of the lack of the spatial and temporal sensitivity of the population denominator generated. A further (typical) limitation of existing studies relates to the qualities of the crime data that they deploy. UK open source police recorded crime data, for example, holds locational accuracy issues at smaller geographical scales due to the way in which the location of a crime is partially anonymised (Malleson and Andresen 2016; Tompson et al. 2015). Additionally, it does not possess fine-grained time stamps (Malleson and Andresen 2016), nor does it identify the type of place in which a crime occurs.

Data limitations aside, we require considering the relation between the ambient population and crime in more detail. Routine activity theory (Cohen and Felson 1979) can be understood to include contrasting propositions about population size (Boivin 2018). On the one hand, as the population size increases it follows that the number of potential offenders and suitable targets (victims) will increase, leading to more crimes taking place. On the other hand, as population size increases it follows that the number of capable guardians (with anyone present being able to perform this role) will also increase, serving to reduce the number of crimes taking place. In this vein, Hipp (2016) cautions against the assumption that the ambient populations are equally likely to perform the roles of motivated offender, target (victim) and guardian. Rather, it is logical to conclude that the qualities of the people present and of the setting itself will hold influence on the likelihood that the roles of motivated offender, target (victim) and guardian will be performed, dependent on the crime type under investigation. It is in these terms that we propose the adoption of an exposed population-at-risk measure defined, with reference to routine activities theory (Cohen and Felson 1979), as the mix of residents and non-residents who may play an active role as an offender, victim or guardian in a specific crime type, present in a spatial unit at a given time. The task remains to advance a theoretically informed definition of the exposed population-at-risk of violent crime, associated with the NTE, in public space. 


\section{The Exposed Population-At-Risk of Violent Crime, Associated with the NTE, in Public Space}

The NTE has no standard definition (Greater London Authority 2017), though it is broadly understood to include the provision of goods, services and experiences (Furedi 2016) in the form of pubs, restaurants, clubs, cinemas, theatres and cultural festivals/events (van Liempt et al. 2015). Here, we utilise an alcohol-specific definition of the NTE, taken to be the sale of alcohol for consumption in bars, pubs, clubs and restaurants (on-trade alcohol outlets) between the hours of early evening to early morning (Wickham 2012). The NTE, attracting a significant transient population, is typically based around a high density of on-trade alcohol premises (Conrow et al. 2015; Grubesic and Pridemore 2011; Snowden 2016) located within or close to town and city centres. Whilst the NTE delivers cultural, social and economic benefits, it is also associated with violent and disorderly behaviours (Finney 2004). Such behaviours exhibit a distinct spatial and temporal patterning, occurring in and around town and city centres and peaking on weekend (Friday and Saturday) evenings (Newton 2015). Wheeler (2019) recommends that a consideration of alcohol consumption and the environmental qualities of areas associated with the NTE provides a useful framework to explore the relationship between violence and the NTE.

Noting that over half of all violent crime has been identified as alcohol-related (Flatley 2016), alcohol consumption is the main activity that takes place in the NTE (Hadfield et al. 2009). The social environment of the NTE induces cumulative alcohol consumption, maintaining or increasing an individual's level of intoxication over the duration of an evening (Bellis et al. 2010; Moore et al. 2007). Alcohol intoxication is associated with heightened aggression and a feeling of power (Finney 2004) and, consequently, the risk of being involved in violence increases with drunkenness (Schnitzer et al. 2010). Further, the clustering of licensed premises into identifiable zones (Conrow et al. 2015; Grubesic and Pridemore 2011; Hadfield et al. 2009; Snowden 2016) generates risky places (Bowers 2014), serving as anchor points for violent crime. Whilst Gmel et al. (2016) concluded, following an international systematic evidential review, that on-trade alcohol premise density held a small causal impact on violent crime, research has found that the level of violent crime to be proportional to the capacity of licensed premises in that setting (Warburton and Shepherd 2004), i.e., a function of the scale of the transient population catered for in the NTE.

NTE settings generate an increased likelihood of accidental or deliberate contact with strangers (Marselle et al. 2012), with crowded and contested spaces such as drinking establishments, fast food takeaways and taxi ranks serving as flashpoints for violent encounters (Hadfield et al. 2009). Similarly, alcohol consumption in these settings raises the prospect of reactive aggression (Moore et al. 2007; Murdoch and Ross 1990) not only by victims but also by the pool of potential guardians who are less prone to prevent an escalation of violence when drunk (Graham et al. 1998). These insights serve to explain the association between the NTE (as a locus for the consumption of alcohol) and violent crime. Specifically, they speak to a shifting temporal propensity of the transient population attracted to the NTE to perform an active role as offender, victim or guardian. It seems plausible that as the evening progresses the likelihood of an individual being an offender or victim will increase, whilst the likelihood of an individual being a guardian will decrease.

In defining the exposed population-at-risk of violent crime in public space, there remain two related issues requiring attention. Firstly, in addition to the transient population attracted to the NTE, it is important to recognise that town and city centres also serve as places of residence, work and shopping etc. What then of the potential of these populations to perform 
an active role as an offender, victim or guardian? Here, we propose that all people using or traversing public space can perform an active role. Noting that city centres host a residential population, we propose that residents can play an active role whilst they traverse public space (i.e., returning to or leaving home), but not when they are at home (i.e., when they are not in public space). Moreover, it seems plausible that as the evening progresses the flow of residents returning home to a NTE setting and the flow of workers and shoppers leaving a NTE setting to return home will decrease in line with the daily rhythms of the city. Given the relation between alcohol consumption and offending, these groups are most likely to perform an active role as a guardian. Thus, it is plausible that as the evening progresses not only will the scale of the exposed population-at-risk decline but also the pool of guardians within that population will decrease. In overview, and in contrast to ambient population measures that seek to capture the total population present in a spatial unit at any given time, the exposed population-at-risk of violent crime in public space requires to be calculated with reference to the population using or traversing public space and not those occupying private space in a spatial unit at any given time.

Secondly, it is necessary to define public space in the NTE. Carmona (2010) classifies urban space as a continuum from clearly private to clearly public space. Public space facilitates the interaction between strangers and acquaintances (Kohn 2004) and is open and visible to everyone (Brighenti 2010). Drawing on the typologies of urban space advanced by Carmona (2010), spaces associated with the NTE can be argued to include public spaces (e.g., streets), private places to which the public are granted access (e.g., pubs and clubs) and public transport.

\section{Data}

\section{Study Area}

The research was conducted in Greater Manchester (GM), a large metropolitan area in the UK. GM has a population of 2.8 million (Office for National Statistics 2018) and is composed of ten local authorities (LA). Each LA contains one or more town/city centre with a corresponding NTE. Manchester city centre is the principal NTE. To illustrate exposed and ambient population-at-risk measures in relation to these NTEs, we utilise the city and town centre boundaries developed to report town centre statistics in England and Wales (Office of the Deputy Prime Minister 2004).

\section{Spatial Unit of Analysis}

The geographical unit used in this research is the Lower Layer Super Output Area (LSOA), which is part of the official census reporting geographies of England and Wales (UK). LSOAs contain areas with similar social and land use characteristics, with their boundaries recognising major physical features on the ground. The study area is composed of 1673 LSOAs, each with a residential population of approximately 1600 people.

\section{Census Data}

Data from the 2011 UK census are used to calculate the residential population for GM at the LSOA level. The data are utilised in the calculation of both the exposed and ambient population-at-risk measures deployed in the research (see below). 


\section{Mobile Phone Data}

A Mobile Phone Origin Destination (MPOD) dataset, provided by Transport for Greater Manchester (TfGM), is used to calculate both the exposed and ambient population-at-risk measures. The MPOD dataset comprises synthesised daily trip chaining (i.e., mobile routing) data (McGuckin and Murakami 1999). The data were collected over a 19-day period in May and July 2013 and then calibrated with reference to the telecommunication company's 33\% market share (on the assumption that the distribution of its subscribers was comparable to the market as a whole), TfGM travel diaries and the demographic characteristics of GM drawn from the 2011 census. The expansion equates to approximately 8.4 million daily trip chains. Of paramount relevance to the calculation of the exposed and ambient population-at-risk measures deployed in this research, the MPOD dataset identifies, on the basis of the first and final trip chain, the end destination (i.e., home neighbourhood) of mobile phone users.

The MPOD data are aggregated to 501 homogenous (in terms of land-use) spatial units, constructed with reference to the location of cellular signal towers. These are denser within town and city centres and sparse within less populated (suburban, semi-rural) areas. Therefore, within town and city centres a MPOD spatial unit equates to a single LSOA, whilst out with town and city centres a MPOD spatial unit equates to approximately three LSOAs. We utilised a geographical information system (GIS) to employ a best-fit technique to distribute MPOD data across LSOAs (Office for National Statistics 2012; Ralphs 2011). Given that the primary objective of the research is to explore the influence of exposed and ambient populations-at-risk on violent crime in public space in town and city centre NTEs, where such crime is concentrated, the relative weakness of the MPOD dataset in less populated areas is outweighed by its strength in town and city centre areas.

Additionally, The MPOD dataset comprises 17 hourly time bins between 06:00 and 22:59, and then a single time bin between 23:00 and 05:59. The larger time bin was created in line with the original motivation to develop the MPOD dataset; i.e., it reflects a period low travel period. To utilise this larger time bin it is necessary to assign a population value to each hour period it contains. We do so, following the approach of Crols and Malleson (2019), through the application of weighting estimates derived from the UK Time Use Survey (Gershuny 2017; Morris et al. 2016), which records the activities of respondents (at 10 min intervals) over the course of a day. In overview (see Table 2, below), this results in a declining population value being assigned to each hour from a peak in 23:00.

\section{Violent Crime in Public Space Data}

The research utilises recorded crime data provided by GM Police for the 2013 calendar year (i.e. from Jan 1 to Dec 31, 2013). For each crime record, the data possess a number of attributes: the Home Office offence code (Home Office 2013), spatial (Cartesian) coordinates, two temporal fields (start date/time and end date/time) and the location type of the offence. To create a violent crime in public space study dataset we undertook the following tasks.

Firstly, we extracted offences classified as 'violence against the person', specifically violence with physical injury and violence without physical injury. Secondly, to meet the requirement that the exposed population-at-risk must be able to play an active role in a crime, we used the location type of each crime record and drew upon Carmona's (2010) typologies of public space to extract violence against the person offences occurring in public spaces (e.g., streets and car parks), private spaces to which the public are granted access (e.g., pubs and 
clubs) and on public transport. The research excluded offences occurring in private spaces (e.g., residential properties, offices and schools). Thirdly, using the spatial coordinates of each crime record, the data were allocated to LSOAs. Finally, using the temporal fields for each crime record the data were distributed in to time bins in line with the MPOD dataset. Over four-fifths $(81.8 \%)$ of violent crimes in public space held the same start and end hour and were therefore allocated to this hour (time-bin). For the remaining one-fifth of crime records, the start and end hour spanned a longer period. This may be because the offence did indeed occur over a longer period or that the victim, offender or guardian (witness) was unable to recall the exact timing of the offence. Here, we applied temporal weights based on the crime record's aoristic signature (Ratcliffe 2002) to assign a fraction (an aoristic value) of the offence to the time bins between its start and end hour. Thus, if a crime recorded as occurring between (start time) 19:00 and (end time) 22:00 on the same day, $t$ would be equal to $1 / 3$. Therefore, a $1 / 3$ weight was applied to the 19:00, 20:00 and 21:00 time bins for that offence. We excluded any crime records in which the time span exceeded $4 \mathrm{~h}$. In line with our treatment of the MPOD dataset, the research considers crime records generated between Saturday 19:00 and Sunday 05:59 to be reflective of a Saturday's NTE. In summary, and following these tasks, the final dataset comprised 17,660 public space violent crimes for the 2013 calendar year.

\section{Methodology}

\section{Calculation of Population-At-Risk Measures}

In this section, we present the strategy deployed to calculate both the ambient and exposed population-at-risk measures. This is achieved through utilising the residential population counts drawn from the 2011 census and the transient (inflow and outflow) population counts drawn from the MPOD dataset. The calculation of the ambient population-at-risk measure is founded on Andresen's (2011) definition of the ambient population comprising the mix of residents and non-residents present in a spatial unit at a given time. Thus, the ambient population-at-risk $(A m b)$ for a given area, in terms of each LSOAs in GM $\left(L_{i}\right)$, sums the residential population count (Res) with the population entering this area ( $I$ as inflows) at a certain time-period $\left(T_{j}\right)$ of day, where $j \leq 24$, whilst subtracting the population exiting this area ( $O$ as outflows) during the same time-period. This can be stated as

$$
\mathrm{Amb}_{L_{i} T_{j}}=\mathrm{Amb}_{L_{i} T_{j-1}}+I_{L_{i} T_{j}}-O_{L_{i} T_{j}}
$$

For each spatial unit $\left(L_{i}\right)$, in each time bin of day $\left(T_{j}\right)$, with the initial time bin $\left(T_{1}\right)$ defined as being 06:00 and equal to the residential population, we calculate the ambient population-at-risk in area $i$ at time-period $T_{1}$ ), as being

$$
\mathrm{Amb}_{L_{i} T_{1}}=\operatorname{Res}_{L_{i}}+I_{L_{i} T_{1}}-O_{L_{i} T_{1}}
$$

To determine the ambient population-at-risk at following time bin of day $\left(T_{1}\right)$, we assume that the residential population at $\left(T_{2}\right)$ is equal to the ambient population at $\left(T_{1}\right)$, where $j \leq 24$. This can be expressed as 


$$
\mathrm{Amb}_{L_{i} T_{2}}=\mathrm{Amb}_{L_{i} T_{1}}+I_{L_{i} T_{2}}-O_{L_{i} T_{2}}
$$

The calculation of the exposed population-at-risk (Exposed) is founded on its definition as the mix of residents and non-residents who may play an active role as an offender, victim or guardian in a specific crime type, present in a spatial unit at a given time. Thus, the violent crime in public space exposed population-at-risk includes residents entering $\left(I_{\text {Home }}\right)$ or exiting their home neighbourhood $\left(O_{\mathrm{Home}}\right.$ ), as well as the non-residents $I_{\mathrm{NonHome} L_{i} T_{j}}$ (the transient population) entering a spatial unit $(i)$ at a given time period ( $j$ ), plus the Exposed population-atrisk in the previous time bin $\left(\operatorname{Exposed}_{L_{i} T_{j-1}}\right)$ and minus those who reached their home $\left(I_{\text {Home } L_{i} T_{j-1}}\right)$ or left the spatial unit $\left(O_{L_{i} T_{j-1}}\right)$ in the previous time bin. Thus, the exposed population-at-risk in a given time period $\left(T_{j}\right)$ can be expressed as

$$
\operatorname{Exposed}_{L_{i} T_{j}}=I_{\mathrm{NonHome}_{i} T_{j}}+I_{\mathrm{Home}_{i} T_{j}}+O_{\mathrm{Home}_{i} T_{j}}+\operatorname{Exposed}_{L_{i} T_{j-1}}-I_{\mathrm{Home}_{i} T_{j-1}}-O_{L_{i} T_{j-}}
$$

At $T_{1}$ we assume that the majority of the residential population will be at home. Therefore, the exposed population-at-risk at this time captures the nonhome-based inflows in to that spatial unit. Determining that $T_{1}=06: 00$ holds precedent in the literature (Newton 2015). Elsewhere, Felson and Poulsen (2003) identify the start of the criminological day as being 5:00, justifying this on the basis of the hourly patterns of crime statistics. In this study (see Fig. 1), the proportion of daily violent crime in public space is at its lowest between 5:00 and 7:00 on Wednesdays and between 7:00 and 8:00 on Saturdays. This being said, the criminological day and the ebb and flow of the citizenry do not necessarily hold perfect accord, as discussed earlier. Finally, it is important to note that the calculation of the exposed population-at-risk, applied here, likely serves to inflate the population capable of performing an active role in public space violent crime, as it will also include those people working in private spaces in the spatial unit.

\section{Analytical Strategy}

The following analytical strategy is deployed to answer the research questions posed in this paper. RQ1 is addressed through a descriptive assessment of the proportion of all violent crime in public space that takes place in different time periods on Wednesdays and Saturdays. Wednesday is selected as a typical weekday, a day when most types of crime have minimum incidence (Towers et al. 2018). Getis Ord $G_{i}^{*}$ (Getis and Ord 1992; Ord and Getis 1995) is used to identify hotspots, LSOAs in which the count of violent crime in public space is significantly higher than in other LSOAs. This statistic was generated using GeoDa software. To support the clarity of the visualisation of this data (as well as that generated in address of RQ3), hotspots (red) are depicted as LSOA centroid points. This approach helps reduce the potential for the varied spatial scale of LSOAs to dominate the visual interpretation of the data. Town and city centres are represented in grey. In interpreting these figures it should be noted that LSOA centroid hotspots appear to circle the town and city centres (grey), a result of the fact that LSOAs cross town and city centre boundaries.

For RQ2, and based on the assumption of monotonic relationship between crime and population-at-risk (Ratcliffe 2002), Spearman's rank correlation coefficient ( $\rho$ as rho) statistic is used to assess the strength of the associations between the ambient and exposed population- 
at-risk measures and violent crime in public space (i.e., to determine whether high values in the population measures are matched by high values in the crime measure). This technique has previously been utilised by Malleson and Andresen (2016) to assess the performance of various population-at-risk measures. RQ3 and RQ4 utilise Gi* (Getis and Ord 1992; Ord and Getis 1995) to identify statistically significant violent crime in public space hotspots informed by the crime rates generated by ambient and exposed population-at-risk measures across multiple time bins. Finally, a descriptive analysis of the ambient and exposed population-at-risk data and the temporally variant count of violent crime in public space are used to address RQ4.

\section{Results}

\section{The Temporal and Spatial Patterning of Violent Crime in Public Space}

In total, 17,660 violent crimes in public space were recorded in the 2013 calendar year. Figure 1 depicts the distinction in the proportion of violent crimes in public space that took place on Wednesdays (a typical weekday) and Saturdays. Each day is represented as starting at 06:00 and ending at 05:59 the following morning to reflect the functioning of the NTE, which commences in the evening and extends in to the early morning of the next day. In overview, $11.4 \%$ all violent crime in public space occurred on Wednesdays in comparison to $20.9 \%$ on Saturdays. Of keynote, the proportions of all violent crimes in public space on Wednesdays and Saturdays are comparable in the period 06:00 to 18:59. However, and at this point, the trend lines diverge. Whilst the proportion of violent crime in public space then falls on Wednesdays, it rises on Saturdays to 22:59, with a significant peak occurring between 01:00 and 01:59. This finding illustrates that crime patterning, the functioning of the NTE, is tied to the working patterns of the week. Figure 2 illustrates the spatial patterning of $\mathrm{G} i *$ violent crime in public space (count) hotspots on Saturdays, which overwhelmingly cluster in and around the main town and city centres of GM. The large cluster at the centre of the map represents Manchester city centre, the main NTE in the region.

\section{The Correlations Between the Exposed and Ambient Population-At-Risk Measures and the Spatial and Temporal Patterning of Violent Crime in Public Space}

Table 1 presents the Spearman's rank-order correlation test results for both the exposed and the ambient population-at-risk measure estimates, for Wednesdays and Saturdays, aggregated in to two time periods (06:00 to 18:59 and 19:00 to 05:59). Two key points emerge from these findings. Firstly, the exposed population-at-risk measure performs better than the ambient population-at-risk measure on each day and across both time periods. This finding is expected; the exposed population-at-risk measure that is a subcomponent of the ambient population-at-risk measure will therefore exhibit greater relative in-group variance. Secondly, the correlation coefficients for both population-atrisk measures exhibit relatively weak strength. A partial explanation for this rests in the extreme over-dispersed spatial and temporal patterning of violent crime in public space. Put simply, a large number of LSOAs in different time periods contain null values meaning that there is limited variance in the dependent variable. However, and fundamentally, this implies that the in-group spatial and temporal variance of each population 
measure does not elide with the spatial and temporal variance of violent crime in public space, where and when such crime exists.

\section{Violent Crime in Public Space Hotspots}

Figure 3 presents the exposed and ambient population-at-risk rate-based $\mathrm{G} i *$ violent crime in public space hotspots on Saturday nights (19:00 to 05:59). Two key findings emerge. Firstly, the most striking distinction between the maps is the absence of hotspots when the exposed population-at-risk measure is deployed and the presence of hotspots when the ambient population-at-risk measure is deployed in Manchester city centre (see the areas circled on both maps), the dominant NTE within GM. Noting that the LSOAs spanning Manchester city centre experience the highest count of violent crime in public space in GM, the implication of this finding is that the exposed population-at-risk-based rates of violent crime in public space in the LSOAs spanning and adjacent to Manchester city centre exhibit a proportionate relationship between population size and crime. In other words, the exposed population-at-risk-based crime rates in the LSOAs comprising Manchester city centre are not significantly higher than the crime rates of other LSOAs in GM. Secondly, and collectively, these maps exhibit both similarity with and distinction to the spatial patterning of the count-based violent crime in public space hotspots, depicted in Fig. 2. Town and city centres still (typically) feature as hotspots but so too do residential areas. In interpreting this distinction a degree of caution must be held. The non-town and city centre hotspots, whilst indicative of disproportionate crime and population counts, relate to LSOAs with (in comparison to town and city-centres) small violent crime in public space counts. In other words, the $\mathrm{G} i *$ violent crime in public space hotspots may vary in their practical significance. This finding, of course, may also be a consequence of the weaker spatial granularity of the MPOD data in non-town and city centre locations.

\section{Violent Crime in Public Space and the Changing Scale of the Exposed Population-At-Risk}

Table 2 presents the hourly (minimum, maximum and mean) estimates of both the exposed and ambient population-at-risk measures across LSOAs on Saturday nights. It also presents an hourly count of violent crime in public space on Saturday nights. Interpreting these data, it is evident that the (maximum and mean) ambient population-at-risk is of a greater scale, though (as proposed earlier) holds more limited in-group variance, than the exposed population-atrisk. The contrast, between the minimum, maximum and mean exposed population-at-risk estimates, serves to highlight the significant variance across space and through time of those capable of performing an active role as an offender, victim and/or guardian. A relatively small number of LSOAs, located in the town and city-centres of GM, attract populations approaching the maximum estimate. Of key significance is the contrast between the hourly exposed population-at-risk estimates and the violent crime in public space counts. Examining Saturday evening (19:00 to 05:59) in detail, it is striking that as the (maximum and mean) exposed population-at-risk falls (19:00 to 22:59) the crime count remains relatively stable. In the later evening (23:00 to 02:59), the crime count rises sharply, whilst the (weighted) exposed population-at-risk continues to fall. 


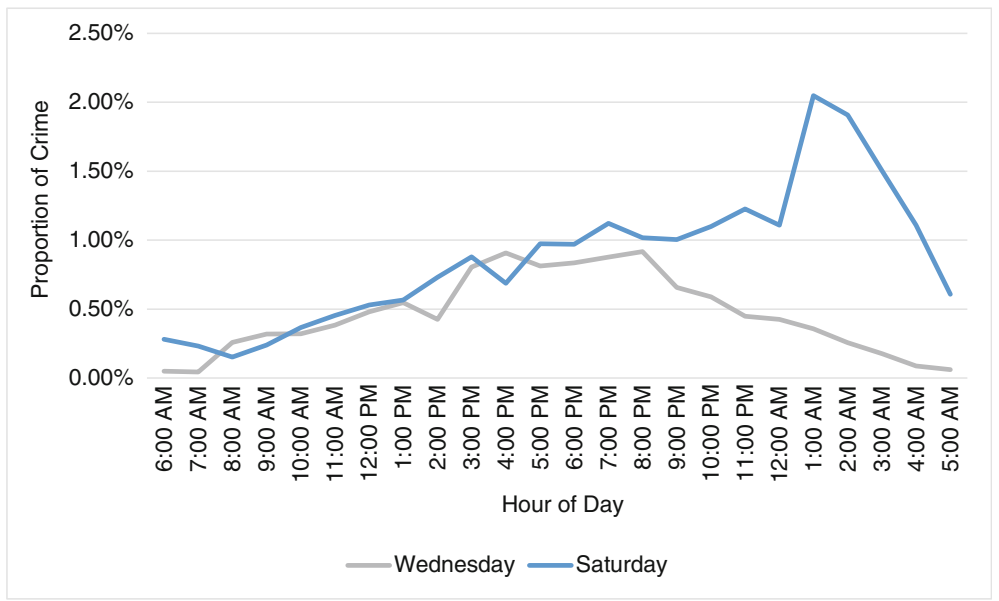

Fig. 1 The proportion of all violent crime in public space on Wednesdays and Saturdays

\section{Discussion}

Sensitive to routine activities theory (Cohen and Felson 1979) and contemporary debates surrounding the application of population denominators to quantify crime, the research reported in this paper is founded on the novel conceptualisation and deployment of an exposed population-at-risk measure, defined as the mix of residents and non-residents who may play an active role as an offender, victim or guardian in a specific crime type, present in a spatial unit at a given time. In these terms, and exploring violent crime in public space, associated with the NTE, it was proposed that resident and non-resident groups could play an active role whilst they occupy and traverse public space, but residents could not whilst they are at home. Moreover, literatures examining the NTE, suggested that the social environment of the NTE induces cumulative alcohol consumption and that the clustering of licensed premises and NTE settings serve as flashpoints for violent encounters. Thus, it was expected that violent crime in public space would tend to cluster in LSOAs in and around town and city centres, as well as to increase over the duration of an evening.

The capacity to evaluate the relevance of the exposed population-at-risk and assess its association with violent crime in public space was made possible by the availability of both novel and fine-grained data on population flows (mobile phone data) and recorded violent crime. The MPOD dataset, combined with census data via a novel methodology, enabled unique exposed and ambient population-at-risk measures to be calculated. Whilst this dataset holds significant merits, particularly its capacity to distinguish user origins and destinations, it also contains weaknesses, particularly its lack of spatial granularity out with town and city centres and its lack of temporal granularity (between 23:00 and 05:59) in a period in which violent crime in public space peaks. This latter issue was addressed through the application of population weights. Nevertheless, and to our knowledge, the qualities of this dataset exceed those deployed in previous studies, and by these terms we judge that the merits of the data outweigh its weaknesses. The locational markers attached to crime records enabled, with reference to a typology of urban space, a unique violent crime in public space dataset to be created. The remainder of this section is devoted to a discussion of the insights generated by the research and their policy relevance. 


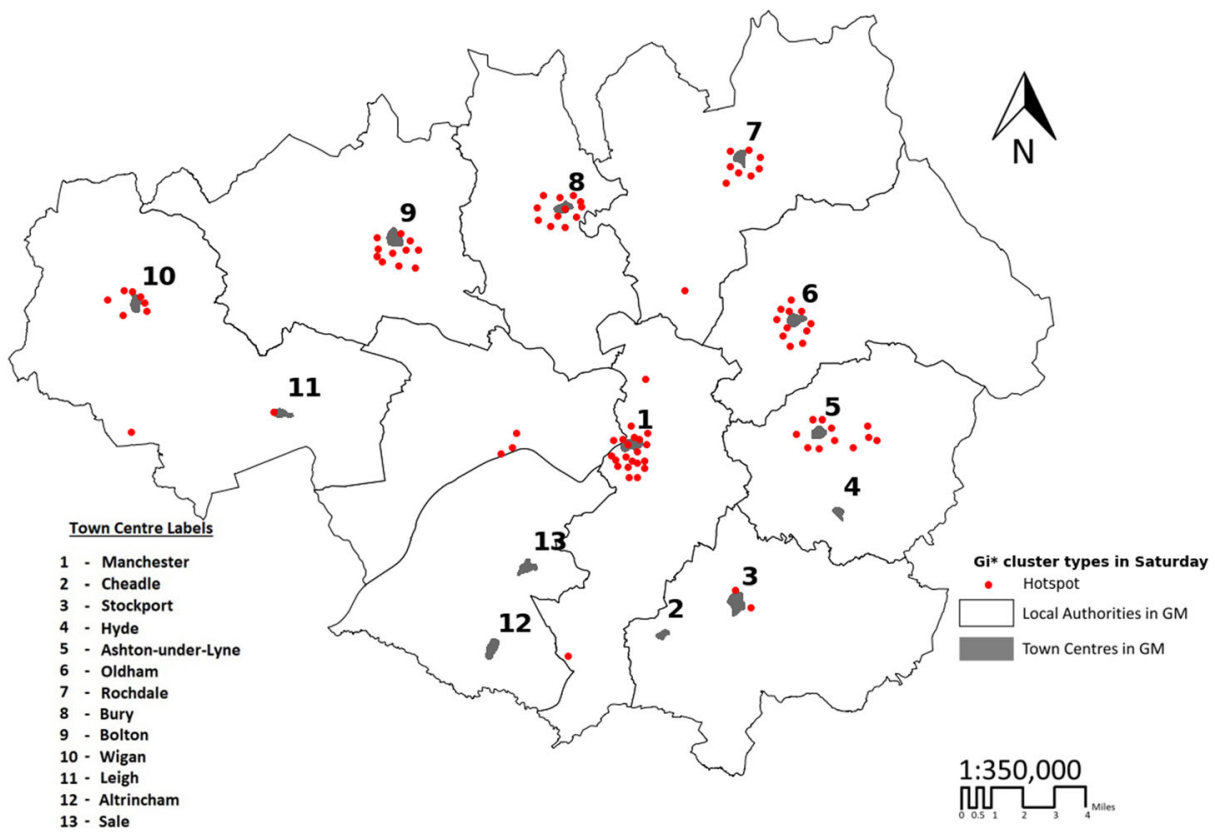

Fig. 2 The spatial patterning of violent crime in public space (count) hotspots on Saturdays

In line with other studies exploring the temporal and spatial patterning of violent crime, the research found the count of violent crime in public space to cluster on specific days of the week and at particular times in the town and city centre locations of the study area (Brunsdon et al. 2007; Newton 2015; Townsley 2008). The research found the associations between both population measures and the spatial and temporal variance of violent crime in public space to be weak. In other words, the in-group spatial and temporal variance of each population measure did not elide with the patterning (concentration) of violent crime in public place. The likely explanation for this finding is twofold. Firstly, violent crime in public space exhibits extreme over dispersion. Secondly, and significantly, the comparison of the time-sensitive population estimates and the count of violent crime in public space found that as the population declines over the course of a Saturday evening, the crime count rises. In other words, the findings are in part consequence of the nature of the phenomenon being investigated. The literature underpinning this study suggested that the NTE induces cumulative alcohol consumption (Bellis et al. 2010; Moore et al. 2007) and that the risk of violence increases with drunkenness (Schnitzer et al. 2010). Therefore, and whilst level of violent crime in public space might be proportionate to the capacity of licensed premises in any given setting (Warburton and Shepherd 2004), it is likely that as the evening progresses and the population falls the number of potential guardians in the exposed population-at-risk declines, whilst the number of potential offenders and victims rises. In other words, the propensity of the exposed population-at-risk to perform active roles as offenders, victims or guardians is both context (crime and setting) and temporally specific. In these terms, it should not be expected that the scale of the population-at-risk correlates with the count of crime.

Turning to consider the findings of the hotspot maps, a key question becomes as follows: what might account for the absence of rate-based hotspots in Manchester city centre when the exposed population-at-risk measure is deployed? One possible explanation is that Manchester 
Table 1 Descriptive statistics of the ambient and exposed populations-at-risk, crime counts, rates and correlations on Wednesday and Saturday

\begin{tabular}{|c|c|c|c|c|c|}
\hline & \multicolumn{2}{|c|}{ Population counts } & \multirow{2}{*}{$\begin{array}{l}\text { Crime } \\
\text { counts }\end{array}$} & \multicolumn{2}{|c|}{ Crime rate by 100,000 population } \\
\hline & $\begin{array}{l}\text { Ambient } \\
\text { population }\end{array}$ & $\begin{array}{l}\text { Exposed } \\
\text { population }\end{array}$ & & $\begin{array}{l}\text { Ambient } \\
\text { population }\end{array}$ & $\begin{array}{l}\text { Exposed } \\
\text { population }\end{array}$ \\
\hline \multicolumn{6}{|l|}{ Wednesday } \\
\hline Mean & 2205.97 & 708.00 & 1.20 & 3.94 & 10.45 \\
\hline Std & 2653.20 & 963.85 & 2.51 & 25.86 & 81.68 \\
\hline Min & 55.39 & 8.01 & 0 & 0.00 & 0.00 \\
\hline 25th percentile $(\mathrm{Q} 1)$ & 823.80 & 285.64 & 0 & 0.00 & 0.00 \\
\hline 50th percentile $(\mathrm{Q} 2)$ & 1439.32 & 489.57 & 1 & 0.00 & 0.00 \\
\hline 75th percentile (Q3) & 2654.67 & 827.72 & 2 & 0.00 & 0.00 \\
\hline $\operatorname{Max}$ & $63,247.15$ & $33,885.00$ & 48 & 1464.02 & 5471.72 \\
\hline \multicolumn{6}{|c|}{ Correlation with violent crime } \\
\hline $\begin{array}{l}\text { rho-Day (06:00 to } \\
\text { 18:59) }\end{array}$ & - & - & - & 0.115 & 0.198 \\
\hline $\begin{array}{l}\text { rho-Night (19:00 to } \\
05: 59)\end{array}$ & - & - & - & 0.05 & 0.122 \\
\hline \multicolumn{6}{|l|}{ Saturday } \\
\hline Mean & 2211.44 & 639.90 & 2.21 & 5.76 & 19.05 \\
\hline Std & 2425.01 & 845.57 & 6.45 & 31.10 & 119.70 \\
\hline Min & 129.54 & 2.97 & 0 & 0.00 & 0.00 \\
\hline 25th percentile $(\mathrm{Q} 1)$ & 912.35 & 286.96 & 0 & 0.00 & 0.00 \\
\hline 50th percentile (Q2) & 1511.85 & 465.61 & 1 & 0.00 & 0.00 \\
\hline 75th percentile (Q3) & 2712.54 & 744.30 & 2 & 0.00 & 0.00 \\
\hline $\operatorname{Max}$ & $68,961.19$ & $41,366.77$ & 150 & 2075.39 & 9847.38 \\
\hline \multicolumn{6}{|c|}{ Correlation with violent crime } \\
\hline $\begin{array}{l}\text { rho-Day (06:00 to } \\
\text { 18:59) }\end{array}$ & - & - & - & 0.103 & 0.161 \\
\hline $\begin{array}{l}\text { rho-Night (19:00 to } \\
05: 59)\end{array}$ & - & - & - & 0.104 & 0.186 \\
\hline
\end{tabular}

city centre holds a broader function (i.e., not exclusively related to alcohol consumption in the NTE) in comparison to those of the other NTEs in GM. Thus, the propensities of the population to perform the roles of offender, victim and guardian may differ in the Manchester NTE in relation to other NTE settings, collectively serving to drive down the crime rate. Perhaps a more likely explanation is that the strategy for managing the Manchester NTE (inclusive of its policing) is distinct from, or indeed impacts upon, the strategies deployed in the other (smaller) NTEs in GM. Given the higher crime count in Manchester city centre, it is possible that a disproportionately greater policing resource is deployed in this setting (in comparison to other settings) serving to temper the crime rate. Whilst further research is required to assess the veracity of these propositions, they are indicative of the potential of accurate population-at-risk measures to inform strategic policy making centred on the functioning and policing of NTEs.

\section{Conclusions}

This paper has sought to contribute to the theoretical and methodological development, as well as the empirical application, of population denominators in the study of crime-specifically, 


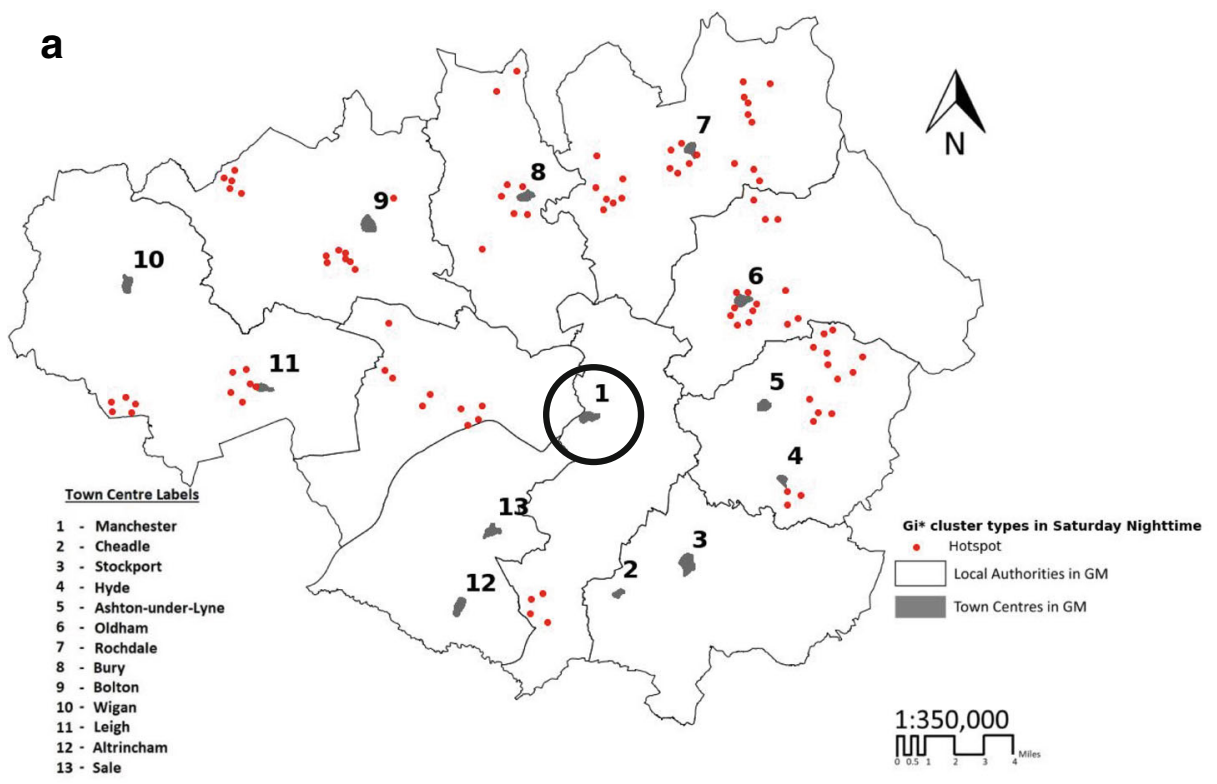

\section{Exposed population-at-risk}

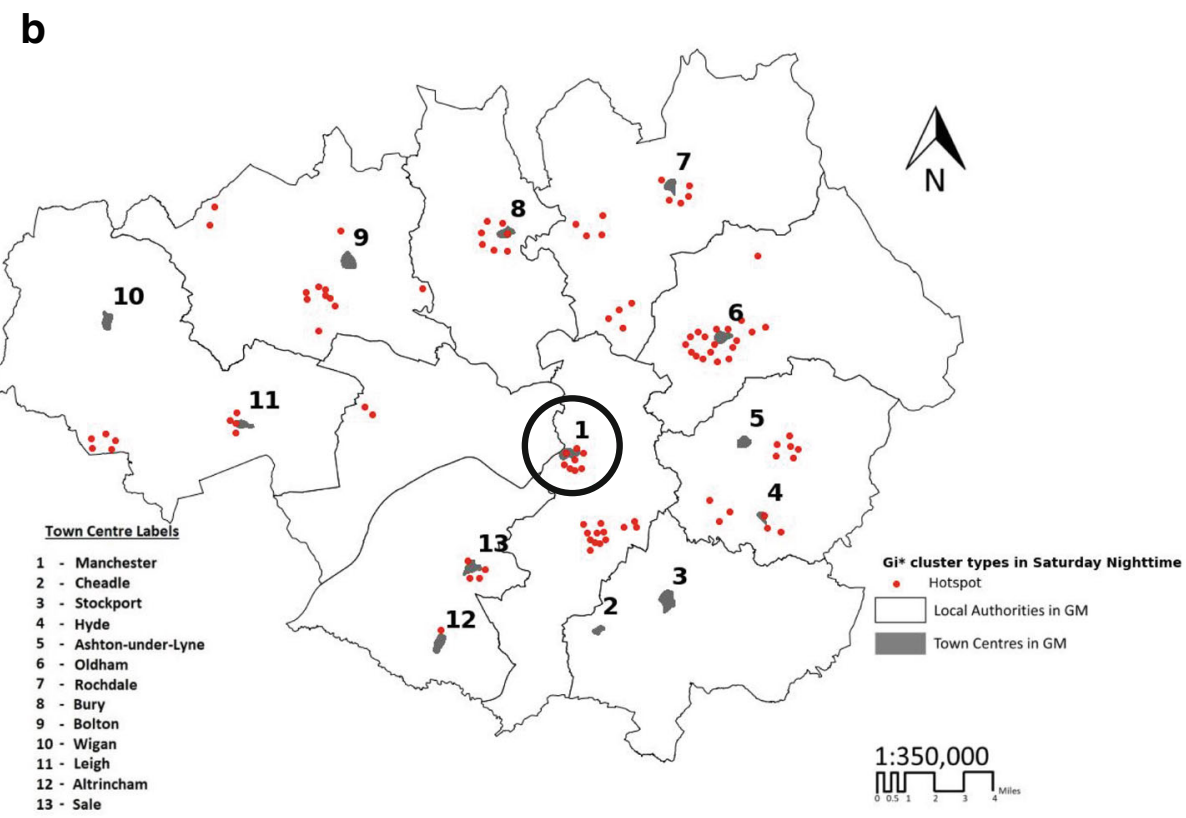

\section{Ambient population-at-risk}

Fig. 3 Exposed (a) and ambient (b) population-at-risk rate-based violent crime in public space hotspots

via a consideration of population mobility. It has introduced the concept of an exposed population-at-risk, defined as the mix of residents and non-residents who may play an active role as an offender, victim or guardian in a specific crime type, present in a spatial unit at a 
Table 2 Hourly population-at-risk estimates and counts of violent crime in public space

\begin{tabular}{|c|c|c|c|c|c|c|c|c|}
\hline \multirow[b]{2}{*}{ Hour } & \multicolumn{3}{|l|}{ Ambient } & \multicolumn{3}{|l|}{ Exposed } & \multirow[t]{2}{*}{ Count of crime } & \multirow[t]{2}{*}{ Weights } \\
\hline & Average & Min & Max & Average & Min & Max & & \\
\hline 06:00 & 2272 & 176 & 43,681 & 84 & 3 & 2190 & 48 & - \\
\hline 07:00 & 2248 & 170 & 44,450 & 180 & 7 & 3647 & 39 & - \\
\hline 08:00 & 2218 & 164 & 45,789 & 305 & 13 & 5350 & 25 & - \\
\hline 09:00 & 2188 & 156 & 49,613 & 419 & 20 & 10,309 & 41 & - \\
\hline $10: 00$ & 2161 & 149 & 55,066 & 507 & 25 & 17,698 & 63 & - \\
\hline $11: 00$ & 2140 & 145 & 59,864 & 589 & 30 & 24,985 & 79 & - \\
\hline $12: 00$ & 2126 & 142 & 64,123 & 665 & 31 & 31,069 & 93 & - \\
\hline $13: 00$ & 2122 & 141 & 67,294 & 722 & 33 & 36,515 & 98 & - \\
\hline $14: 00$ & 2125 & 140 & 68,940 & 765 & 34 & 40,348 & 129 & - \\
\hline $15: 00$ & 2131 & 136 & 68,961 & 796 & 37 & 41,367 & 156 & - \\
\hline $16: 00$ & 2138 & 130 & 67,101 & 808 & 36 & 40,529 & 121 & - \\
\hline $17: 00$ & 2139 & 144 & 64,139 & 819 & 39 & 38,009 & 172 & - \\
\hline $18: 00$ & 2182 & 153 & 60,935 & 821 & 43 & 34,447 & 173 & - \\
\hline $19: 00$ & 2218 & 159 & 55,811 & 774 & 38 & 28,035 & 198 & - \\
\hline $20: 00$ & 2237 & 163 & 51,786 & 735 & 36 & 20,443 & 182 & - \\
\hline $21: 00$ & 2249 & 164 & 49,062 & 722 & 35 & 15,500 & 179 & - \\
\hline $22: 00$ & 2259 & 165 & 47,131 & 714 & 34 & 14,218 & 197 & - \\
\hline $23: 00$ & 2267 & 164 & 46,391 & 748 & 36 & 12,802 & 220 & 0.4 \\
\hline 00:00 & 2272 & 163 & 45,984 & 713 & 34 & 11,992 & 197 & 0.22 \\
\hline 01:00 & 2275 & 163 & 45,706 & 706 & 34 & 11,679 & 369 & 0.15 \\
\hline 02:00 & 2276 & 163 & 45,595 & 683 & 33 & 11,272 & 343 & 0.06 \\
\hline 03:00 & 2277 & 162 & 45,540 & 676 & 32 & 11,137 & 269 & 0.03 \\
\hline 04:00 & 2278 & 162 & 45,447 & 689 & 33 & 11,229 & 197 & 0.05 \\
\hline 05:00 & 2280 & 162 & 45,262 & 717 & 34 & 11,460 & 107 & 0.1 \\
\hline
\end{tabular}

given time. Through integrating census with novel and fine-grained mobile phone and recorded crime data via a novel methodology, and with reference to literatures exploring violence and the NTE, the research generated a theoretically informed exposed population-atrisk measure to explore violent crime in public space. The resultant assessment of this population measure discerned a temporally non-linear association between population size and violent crime in public space, providing empirical evidence of an expected though untested relationship between violence and the NTE. It also demonstrated the potential of the exposed population-at-risk measure to inform both policy-making and evaluation, whilst also demonstrating that the potential of novel data to be deployed in increasingly fine-grained resolution holds limitations in its value to help explain and address crime.

Funding Information This work was supported by the UK Economic and Social Research Council (ESRC) under grant ES/P009301/1 (understanding inequalities).

Open Access This article is licensed under a Creative Commons Attribution 4.0 International License, which permits use, sharing, adaptation, distribution and reproduction in any medium or format, as long as you give appropriate credit to the original author(s) and the source, provide a link to the Creative Commons licence, and indicate if changes were made. The images or other third party material in this article are included in the article's Creative Commons licence, unless indicated otherwise in a credit line to the material. If material is not included in the article's Creative Commons licence and your intended use is not permitted by statutory regulation or exceeds the permitted use, you will need to obtain permission directly from the copyright holder. To view a copy of this licence, visit http://creativecommons.org/licenses/by/4.0/. 


\section{References}

Andresen, M. a. (2011). The ambient population and crime analysis. The Professional Geographer, 63(2), 193212. https://doi.org/10.1080/00330124.2010.547151.

Bellis, M. A., Hughes, K., Quigg, Z., Morleo, M., Jarman, I., \& Lisboa, P. (2010). Cross-sectional measures and modelled estimates of blood alcohol levels in UK nightlife and their relationships with drinking behaviours and observed signs of inebriation. Substance Abuse Treatment, Prevention, and Policy, 5(1), 5. https://doi. org/10.1186/1747-597X-5-5.

Boggs, S. L. (1965). Urban Crime Patterns. American Sociological Review, 30(6), 899. https://doi.org/10.2307 12090968.

Bogomolov, A., Lepri, B., Staiano, J., Oliver, N., Pianesi, F., \& Pentland, A. (2014). Once upon a crime: towards crime prediction from demographics and Mobile data. In Proceedings of the 16th international conference on multimodal interaction - ICMI '14 (pp. 427-434). New York: ACM Press. https://doi.org/10.1145 /2663204.2663254.

Boivin, R. (2018). Routine activity, population(s) and crime: spatial heterogeneity and conflicting propositions about the neighborhood crime-population link. Applied Geography, 95(May), 79-87. https://doi.org/10.1016 /j.apgeog.2018.04.016.

Boivin, R., \& Felson, M. (2018). Crimes by visitors versus crimes by residents: the influence of visitor inflows. Journal of Quantitative Criminology, 34(2), 465-480. https://doi.org/10.1007/s10940-017-9341-1.

Bowers, K. (2014). Risky facilities: crime radiators or crime absorbers? A comparison of internal and external levels of theft. Journal of Quantitative Criminology, 30(3), 389-414. https://doi.org/10.1007/s10940-0139208-z.

Braithwaite, J. (1989). Crime, shame and reintegration. Cambridge: Cambridge University Press. https://oi. org/10.1017/CBO9780511804618.

Brighenti, A. M. (2010). Visibility in social theory and social research. London: Palgrave Macmillan UK. https://doi.org/10.1057/9780230282056.

Brunsdon, C., Corcoran, J., \& Higgs, G. (2007). Visualising space and time in crime patterns: a comparison of methods. Computers, Environment and Urban Systems, 31(1), 52-75. https://doi.org/10.1016/j. compenvurbsys.2005.07.009.

Carmona, M. (2010). Contemporary public space, part two: classification. Journal of Urban Design, 15(2), 157173. https://doi.org/10.1080/13574801003638111.

Chainey, S., \& Ratcliffe, J. (2005). GIS and crime mapping. Hoboken: Wiley.

Cohen, L. E., \& Felson, M. (1979). Social change and crime rate trends: a routine activity approach. American Sociological Review, 44(4), 588. https://doi.org/10.2307/2094589.

Conrow, L., Aldstadt, J., \& Mendoza, N. S. (2015). A spatio-temporal analysis of on-premises alcohol outlets and violent crime events in Buffalo, NY. Applied Geography, 58, 198-205. https://doi.org/10.1016/j. apgeog.2015.02.006.

Crols, T., \& Malleson, N. (2019). Quantifying the ambient population using hourly population footfall data and an agent-based model of daily mobility. Geoinformatica, 23, 201-220.

Felson, M., \& Boivin, R. (2015). Daily crime flows within a city. Crime Science, 4(1), 31. https://doi.org/10.1186 /s40163-015-0039-0.

Felson, M., \& Poulsen, E. (2003). Simple indicators of crime by time of day. International Journal of Forecasting, 19, 595-601.

Finney, A. (2004). Violence in the night-time economy: Key findings from the research. Home Office Report. http://www.popcenter.org/problems/assaultsinbars/pdfs/finney_2004.pdf. Accessed 16 May 2019.

Flatley, J. (2016). Crime statistics, focus on violent crime and sexual offences, 2013/14. Office for National Statistics. https://www.ons.gov.uk/peoplepopulationandcommunity/crimeandjustice/compendium/focuson violentcrimeandsexualoffences/2015-02-12. .

Furedi, F. (2016). Forward into the night report: the changing landscape of Britain's cultural and economic life. Night Time Industries Association.

Gershuny, J. (2017) United Kingdom Time Use Survey, 2014-2015.

Getis, A., \& Ord, J. K. (1992). The analysis of spatial association by use of distance statistics. Geographical Analysis, 24(3), 189-206. https://doi.org/10.1111/j.1538-4632.1992.tb00261.x.

Gmel, G., Holmes, J., \& Studer, J. (2016). Are alcohol outlet densities strongly associated with alcohol-related outcomes? A critical review of recent evidence. Drug and Alcohol Review, 35(1), 40-54. https://doi. org/10.1111/dar.12304.

Graham, K., Leonard, K. E., Room, R., Wild, T. C., Pihl, R. O., Bois, C., \& Single, E. (1998). Current directions in research on understanding and preventing intoxicated aggression. Addiction, 93(5), 659-676. https://doi. org/10.1046/j.1360-0443.1998.9356593.x. 
Greater London Authority. (2017). Culture and the night time economy: supplementary planning guidance. https://www.london.gov.uk/sites/default/files/ntc_spg_2017_a4_public_consultation_report_fa_0.pdf. Accessed 16 May 2019.

Grubesic, T. H., \& Pridemore, W. A. (2011). Alcohol outlets and clusters of violence. International Journal of Health Geographics, 10(1), 30. https://doi.org/10.1186/1476-072X-10-30.

Hadfield, P., Lister, S., \& Traynor, P. (2009). This town's a different town today. Criminology \& Criminal Justice, 9(4), 465-485. https://doi.org/10.1177/1748895809343409.

Hanaoka, K. (2018). New insights on relationships between street crimes and ambient population: Use of hourly population data estimated from mobile phone users' locations. Environment and Planning B: Urban Analytics and City Science, 45(2), 295-311. https://doi.org/10.1177/0265813516672454.

Hipp, J. R. (2016). General theory of spatial crime patterns. Criminology, 54(4), 653-679. https://doi.org/10.1111 /1745-9125.12117.

Hipp, J. R., Bates, C., Lichman, M., \& Smyth, P. (2018). Using social media to measure temporal ambient population: does it help explain local crime rates? Justice Quarterly, 1-31. https://doi.org/10.1080 /07418825.2018.1445276.

Home Office. (2013). User guide to home office crime statistics. Home Office. https://assets.publishing.service. gov.uk/government/uploads/system/uploads/attachment_data/file/116226/user-guide-crime-statistics.pdf. Accessed 16 May 2019.

Kohn, M. (2004). Brave new neighborhoods. Abingdon: Routledge. https://doi.org/10.4324/9780203495117.

Malleson, N., \& Andresen, M. A. (2015). The impact of using social media data in crime rate calculations: shifting hot spots and changing spatial patterns. Cartography and Geographic Information Science, 42(2), 112-121. https://doi.org/10.1080/15230406.2014.905756.

Malleson, N., \& Andresen, M. A. (2016). Exploring the impact of ambient population measures on London crime hotspots. Journal of Criminal Justice, 46, 52-63. https://doi.org/10.1016/j.jcrimjus.2016.03.002.

Marselle, M., Wootton, A. B., \& Hamilton, M. G. (2012). A design against crime intervention to reduce violence in the night-time economy. Security Journal, 25(2), 116-133. https://doi.org/10.1057/sj.2011.14.

Mburu, L. W., \& Helbich, M. (2016). Crime risk estimation with a commuter-harmonized ambient population. Annals of the American Association of Geographers, 106(4), 804-818. https://doi.org/10.1080 /24694452.2016.1163252.

McGuckin, N., \& Murakami, E. (1999). Examining trip-chaining behavior: comparison of travel by men and women. Transportation Research Record: Journal of the Transportation Research Board, 1693(1), 79-85. https://doi.org/10.3141/1693-12.

Moore, S., Shepherd, J., Perham, N., \& Cusens, B. (2007). The prevalence of alcohol intoxication in the nighttime economy. Alcohol and Alcoholism, 42(6), 629-634. https://doi.org/10.1093/alcalc/agm054.

Morris, S., Humphrey, A., Cabrera Alvarez, P., \& D’Lima, O. (2016). The UK Time Use Survey 2014-2015. Technical Report. Centre for Time Use Research. Oxford: University of Oxford.

Murdoch, D., \& Ross, D. (1990). Alcohol and crimes of violence: present issues. International Journal of the Addictions, 25(9), 1065-1081. https://doi.org/10.3109/10826089009058873.

Newton, A. (2015). Crime and the NTE: multi-classification crime (MCC) hot spots in time and space. Crime Science, 4(1), 30. https://doi.org/10.1186/s40163-015-0040-7.

Office for National Statistics. (2012). An overview of building 2011 census estimates from output areas. Office for National Statistics.

Office for National Statistics. (2018). Population estimates for UK, England and Wales Scotland, and Northern Ireland Mid-2010 population estimates. Office for National Statistics. https://www.ons.gov. uk/peoplepopulationandcommunity/populationandmigration/populationestimates/bulletins/annualmidyear populationestimates/mid2017. Accessed 16 May 2019.

Office of the Deputy Prime Minister. (2004). Producing boundaries and statistics for town Centres: England and Wales 2000. Office of the Deputy Prime Minister. http://www.communities.gov. uk/documents/planningandbuilding/pdf/135640.pdf

Ord, J. K., \& Getis, A. (1995). Local spatial autocorrelation statistics: distributional issues and an application. Geographical Analysis, 27(4), 286-306. https://doi.org/10.1111/j.1538-4632.1995.tb00912.x.

Ralphs, M. (2011). Exploring the performance of best fitting to provide ONS data for non standard geographical areas. Office for National Statistics.

Ratcliffe, J. H. (2002). Aoristic signatures and the spatio-temporal analysis of high volume crime patterns. Journal of Quantitative Criminology, 18(1), 23-43. https://doi.org/10.1023/A:1013240828824.

Rotolo, T., \& Tittle, C. R. (2006). Population size, change, and crime in U.S. cities. Journal of Quantitative Criminology, 22(4), 341-367. https://doi.org/10.1007/s10940-006-9015-x.

Schnitzer, S., Bellis, M. A., Anderson, Z., Hughes, K., Calafat, A., Juan, M., \& Kokkevi, A. (2010). Nightlife violence: a gender-specific view on risk factors for violence in nightlife settings: a cross-sectional study in 
nine European countries. Journal of Interpersonal Violence, 25(6), 1094-1112. https://doi.org/10.1177 $/ 0886260509340549$.

Sherman, L. W., Gartin, P. R., \& Buerger, M. E. (1989). Hot spots of predatory crime: Routine activities and the criminology of place. Criminology, 27(1), 27-56. https://doi.org/10.1111/j.1745-9125.1989.tb00862.x.

Siegel, J. A., \& Williams, L. M. (2003). The relationship between child sexual abuse and female delinquency and crime: a prospective study. Journal of Research in Crime and Delinquency, 40(1), 71-94. https://doi. org/10.1177/0022427802239254.

Snowden, A. J. (2016). Alcohol outlet density and intimate partner violence in a nonmetropolitan college town: accounting for neighborhood characteristics and alcohol outlet types. Violence and Victims, 31(1), 111-123. https://doi.org/10.1891/0886-6708.VV-D-13-00120.

Song, G., Liu, L., Bernasco, W., Xiao, L., Zhou, S., \& Liao, W. (2018). Testing indicators of risk populations for theft from the person across space and time: The significance of mobility and outdoor activity. Annals of the American Association of Geographers, 108(5), 1370-1388. https://doi.org/10.1080 /24694452.2017.1414580.

Stults, B. J., \& Hasbrouck, M. (2015). The effect of commuting on city-level crime rates. Journal of Quantitative Criminology, 31(2), 331-350. https://doi.org/10.1007/s10940-015-9251-z.

Tompson, L., Johnson, S., Ashby, M., Perkins, C., \& Edwards, P. (2015). UK open source crime data: accuracy and possibilities for research. Cartography and Geographic Information Science, 42(2), 97-111. https://doi. org/10.1080/15230406.2014.972456.

Towers, S., Chen, S., Malik, A., \& Ebert, D. (2018). Factors influencing temporal patterns in crime in a large American city: a predictive analytics perspective. PLoS One, 13(10), 1-27. https://doi.org/10.1371/journal. pone.0205151.

Townsley, M. (2008). Visualising space time patterns in crime: the hotspot plot. Crime Patterns and Analysis, 1(1), 61-74 http://eccajournal.org/V1N1S2008/Townsley.pdf.

van Liempt, I., van Aalst, I., \& Schwanen, T. (2015). Introduction: geographies of the urban night. Urban Studies, 52(3), 407-421. https://doi.org/10.1177/0042098014552933.

Warburton, A. L., \& Shepherd, J. P. (2004). An evaluation of the effectiveness of new policies designed to prevent and manage violence through an interagency approach. Welsh Assembly Government, Wales Office of Research and Development.

Weisburd, D., Groff, E. R., \& Yang, S.-M. (2012). The criminology of place. Oxford: Oxford University Press. https://oi.org/10.1093/acprof:oso/9780195369083.001.0001.

Wheeler, A. P. (2019). Quantifying the local and spatial effects of alcohol outlets on crime. Crime \& Delinquency, 65(6), 845-871. https://doi.org/10.1177/0011128718806692.

Wickham, M. (2012). Alcohol consumption in the night-time economy. London: Greater London Authority http://www.london.gov.uk/sites/default/files/alcohol_consumption_0.pdf. Accessed 16 May 2019.

Publisher's Note Springer Nature remains neutral with regard to jurisdictional claims in published maps and institutional affiliations. 